\title{
Immunohistochemical evaluation of lymphocyte populations in the nictitans glands of normal dogs and dogs with keratoconjunctivitis sicca
}

\author{
David L. Williams* and Alice Tighe \\ Department of Veterinary Medicine, University of Cambridge, Cambridge CB3 OES, UK
}

\begin{abstract}
Idiopathic canine keratoconjunctivitis sicca (iKCS) is a common condition of the canine eye involving a deficiency in aqueous tear production which is commonly held to have an immune-mediated, as most probably an autoimmune aetiopathogenesis. Yet to date no direct evaluation has been made of the inflammatory cell populations in the lacrimal tissue of dogs with iKCS. Here we sought to quantify T and B lymphocyte populations in the lacrimal tissue of the nictitans glands of dogs with iKCS those with neurological KCS (nKCS)and also in dogs with tear production within the recognized normal levels and no ocular surface signs of KCS. Nictitans glands were obtained from 10 healthy dogs with no signs or history consistent with KCS at post-mortem or after enucleation. Nictitans glands were also obtained at parotid duct transposition surgery from ten dogs with idiopathic KCS and three with neurogenic KCS. Histological sections form the lacrimal tissue were processed immunohistochemically with primary monoclonal antibodies recognizing the T lymphocyte CD3 antigen and the B lymphocyte CD79a antigen. Cell numbers were counted in 10 randomly sampled representative high-power fields in five sections. Statistical significance of differences in cell numbers was determined using analysis of variance with significance achieved at $\mathrm{p}=0.05$. Nictitans glands from dogs with iKCS showed elevated numbers of T and B lymphocytes compared with those from dogs with normal tear production. The increase in the $T$ cell population was highly statistically significant $(p=0.0025)$ while the increase in B cells, while statistically significant was less pronouncedly so $(\mathrm{p}=0.049)$. T and B lymphocyte numbers were not significantly elevated in nictitans glands from dogs with neurogenic KCS compared with those in dogs with normal tear production. The elevation in the T cell population seen in dogs with idiopathic KCS strongly supports the widely held assumption that this disease is an immune-mediated and probably autoimmune. The lack of increase in $\mathrm{T}$ cell populations in dogs with nKCS strongly suggests that the changes in iKCS are causing the tear deficiency and not resulting from it.
\end{abstract}

Keywords: Autoimmunity, Dog, Eye, Keratoconjunctivitis sicca, Lymphocyte.

\section{Introduction}

Idiopathic keratoconjunctivitis sicca (iKCS) is seen in a number of breeds of dog and is generally considered to have an immunological, and probably an autoimmune aetiopathogenesis (Williams, 2008). While work over twenty years ago showed that the infiltrating cell population in lacrimal and nictitans glands of such dogs was lymphocytic in nature (Kaswan et al., 1984), further work characterizing these populations is lacking. The ameliorative lacrimostimulatory action of the immunomodulatory drugs cyclosporine (Kaswan and Salisbury, 1990; Olivero, 1991), tacrolimus (Berdoulay et al., 2005) and pimecrolimus (Nell et al., 2005) further suggests an immune-mediated disease process in this condition although these calcineurin inhibitors may exert their lacrimogenic influence through mechanisms other than, or in addition to their immuno-modulatory action (Williams, 1997a; Gao et al., 1998; Yoshida et al., 1999). One paper has evaluated the changes in lacrimal gland lymphocyte populations after the use of cyclosporine but without first characterising the cells infiltrating the gland (Izci et al., 2002). The importance of $\mathrm{T}$ cells in pathogenesis of autoimmune disease has been recognized for some time (Allison, 1974).

In this study we aimed to determine the immunophenotype of inflammatory cells infiltrating the tear-producing gland of the third eyelid, the nictitans gland. We compared cell numbers in the nictitans glands of normal dogs, in dogs with idiopathic KCS (iKCS) and in those with neurological KCS (nKCS) where an autoimmune pathogenesis is not central to the failure of tear production (Williams, 2008). As will be noted below, antibodies directed against canine CD4 and CD8 epitopes do not exist as yet for fixed canine tissue (Williams, 1997b) and thus at present all we can do is to determine the $\mathrm{T}$ or $\mathrm{B}$ immunophenotype of infiltrating mononuclear cells. Clearly in future work more detailed immunophenotyping will be required to ascertain the presumed CD4 phenotype of these $\mathrm{T}$ lymphocytes. We postulate that the dogs affected with idiopathic KCS 
(iKCS) will show an increase in $\mathrm{T}$ lymphocytes compared to dogs with normal tear production but that dogs in which dry eye is neurological in origin (nKCS) will not have these infiltrating cell populations.

By comparing nictitating membranes in dogs with iKCS with those from nKCS animals, we aim to show that the changes in lymphocyte populations in the gland are a cause of disease rather than merely an effect of deficiency in tear production, in which case increase in inflammatory cell populations would be seen in all dry eyes regardless of pathogenesis..

\section{Materials and Methods}

All animals involved in this study were examined ophthalmoscopically using direct ophthalmoscopy and slit lamp biomicroscopy by one clinician (DW). Each animal underwent a standard Schirmer I tear test (STT) as previously described (Gelatt et al., 1975). Ten of these animals were considered to be affected by iKCS given their breed type and bilateral nature of the disease with STT values under $10 \mathrm{~mm} / \mathrm{min}$. Three of the cases were deemed to be nKCS because of their unilateral nature and the coexistence of an ipsilateral dry external nares, caused by denervation of the medial nasal gland (Scagliotti, 1991).

All iKCS animals had previously been noted to be cyclosporine-responsive but for financial reasons the drug had not been used for a minimum of three months in each animal before parotid duct transposition and concurrent nictitans gland biopsy. No nKCS cases had responded to topical cyclosporine and the drug had not been used in these animals for three months before PDT and nicitans gland biopsy. The median duration of cyclosporine treatment was 42 days with a maximum time of 56 days and minimum of 28 days. No other immunomodulatory agents such as tacrolimus had been used in these animals. The reduction in inflammatory cell numbers caused by use of cyclosporine (Kaswan and Salisbury, 1990; Williams, 1997b, 2008) would have negated the results were dogs on treatment to have been used.

While we have no direct evidence on the time-course of recovery in inflammatory lesions in $\mathrm{iKCS}$, it is reported that cessation of topical cyclosporine treatment leads to recurrence of inflammatory disease in under one month (Williams et al., 1995), hence the choice of three months to ensure that lacrimal pathology would have reverted to pre-treatment levels. Ocular surface health had, in that period, been maintained with topical tear replacement alone using Viscotears (Alcon, Fort Worth TX) or Remend (Bayer, Newbury UK). Full owner consent was given for the removal of tissue for this study. This study conforms to the guidelines of the ethical review committee of the University of Cambridge Veterinary School.

Nictitans glands were removed from 13 dogs with severe KCS treated surgically by parotid duct transposition (Glenn and Lawson, 1971). Ten samples of nictitans gland were obtained from dogs euthanased for non-ocular disease which had, before death, been determined to have normal levels of tear production $(15-25 \mathrm{~mm} / \mathrm{min}$ using a standard Schirmer 1 tear test) or from eyes enucleated for diseases in which the ocular surface was not involved and in which tear production was normal.

All animals were clinical patients at the Queen's veterinary school hospital, University of Cambridge, treated under the guidelines of the ethical review committee of that institution. Owner consent was obtained for the recovery of nictitans gland lacrimal tissue. Nictitans gland tissue was placed in buffered $10 \%$ formalin for 24 hours before being routinely processed for histological examination. One tissue section was stained with haematoxylin and eosin while others underwent an indirect immunoperoxidase staining procedure as previously described (Huang, 1975).

All sections were pre-treated by microwaving in a citrate buffer at $\mathrm{pH} 6.0$ for 10 minutes prior to immunostaining. Primary monoclonal antibodies used in this technique were directed against canine CD3 and CD79a epitopes (Dako), used at 1:150 and 1:500 to identify $\mathrm{T}$ and B lymphocytes respectively (Williams, 1997b). The second layer was applied using an antimouse Ig polymerized reporter enzyme staining system (Impress, Vector) and visulaised with 3,4Diaminobenzidine (DAB, Vector) before dehydrating and mounting. Positive control tissue was canine reactive lymph node and a negative control mouse IgG1 antibody (Dako) was used to rule out any non-specific staining on all test sections. Total number of cells together with numbers of cells expressing CD3 and CD79a epitopes were counted in 10 randomly chosen areas of the lacrimal tissue of the nictans gland from each animal at a magnification of $x 400$. The random nature of histomorphometric sampling was assured as previously described (Busche et al., 1997). The observer obtaining the datasets of cell numbers was blinded to the identity of the animal involved and its level of tear production.

Statistical significance of differences in numbers of $\mathrm{T}$ and B cells in nictitans glands of dogs with normal tear production, dogs with iKCS and dogs with nKCS was determined by evaluating analysis of variance with significance deemed to have been reached at $p=0.05$.

\section{Results}

The signalment of the dogs from which tissue was harvested are given in Table 1 together with the presumptive diagnosis and Schirmer tear test of the eye from which tissue was harvested. Representative samples of haematoxylin and eosin stained and immunoperoxidase stained tissue sections are shown in Figures 1A, 1B and 1C. 


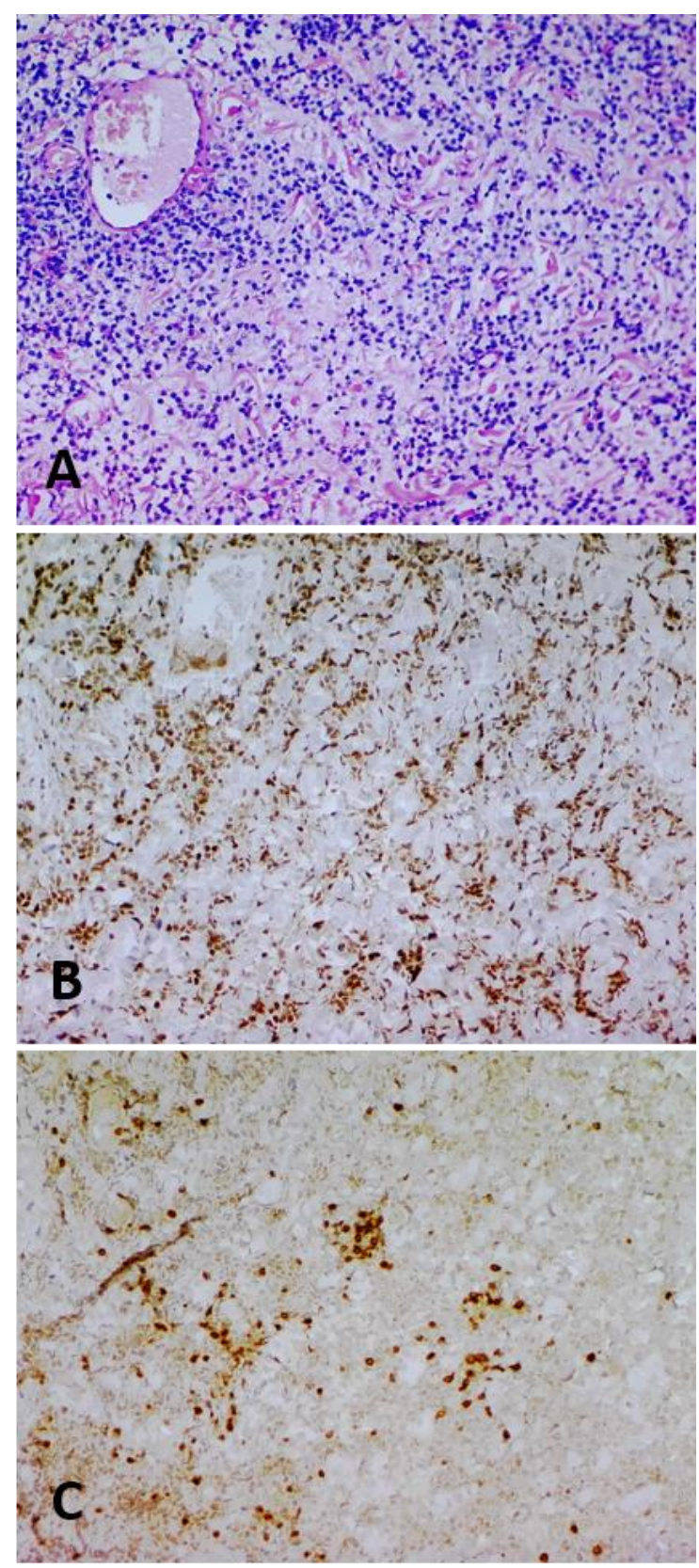

Fig. 1. Consecutive sections of nictitans gland from a representative iKCS case (case 1) all originally at x20 magnification. (A): Haematoxylin and eosin stained section of gland. (B): CD3-immunostained section of nictitans gland. (C): CD79a-immunostained section of nictitans gland.

The total lymphocyte numbers and numbers of CD3and CD79a-expressing cells for each dog are given in Table 2. The mean total lymphocyte numbers and numbers of CD3- and CD79a-expressing cells for nictitans tissue from dogs with normal tear production, with iKCS and with nKCS together with $\mathrm{p}$ values showing the statistical significance of the difference between KCS data and that from unaffected dogs are given in Table 3.

\section{Discussion}

Idiopathic canine KCS is a condition which is cyclosporine -responsive, seen in specific breeds of dog such as the West Highland White terrier, the Cocker spaniel, the Lhasa Apso and Shih tzu,, recognized more in female in than male dogs and generally noted to occur in middle aged animals (Williams, 2008). It is similar in some respects to the autoimmune dry eye syndrome Sjogrens syndrome seen in humans (Mircheff, 2003) and to rodent models such as the lpr/lpr mouse in which a mutation in the Fas gene leads to failure of apoptosis in lymphocytes (Jabs et al., 1997), and the non-obese diabetic (NOD) mouse (Robinson et al., 1998). These rodent and human conditions are characterised by a CD4-expressing helper T cell infiltration (Adamson et al., 1983). These findings, together with Kaswan's early studies showing the lymphocytic nature of the inflammatory infiltrate in the lacrimal and nictitans glands of affected dogs (Kaswan et al., 1984) has led to the very reasonable presumption that idiopathic canine KCS is an autoimmune disease. The finding that topical cyclosporine ameliorates the condition strengthens this hypothesis but yet to date no studies have reported the detailed phenotype of the mononuclear inflammatory cell infiltrate in the lacrimal tissue from affected eyes. While Izci and colleagues (2002) have reported changes in the inflammatory cell populations in KCSaffected animals treated with topical cyclosporine they did not document the initial quantitative findings in the lacrimal tissue of these animals and compare this with cell numbers in normal lacrimal tissue (Kaswan and Salisbury, 1990). Here we sought to do exactly that.

We have shown that mononuclear inflammatory cells in the nictitans gland are significantly increased in iKCS but not in nKCS and that CD3-expressing T cells are particularly highly elevated in number in iKCS. The fact that this increase is not seen in nKCS strongly suggests that the increase is not merely caused as a reaction to the ocular surface drying pathology but is itself the cause of the condition.

The centrality of CD3-expressing $T$ cells in autoimmune disease has been recognized for many decades with CD4 helper/regulatory $\mathrm{T}$ cells as the critical effector cells in these diseases (O'Garra et al., 1997). Unfortunately monoclonal antibodies directed against canine CD4 and CD8 as produced through the Canine Leucocyte Antigen Workshop (CLAW) in the 1980s (Cobbold and Metcalfe, 1994) are effective only in frozen tissue and this was not available for the present study. Nevertheless this study supports the hypothesis that previously termed idiopathic canine KCS is indeed an immune-mediated KCS given the T cell population noted in the tear-producing tissue studied, while in neurogenic KCS the increased numbers of CD3-expressing $\mathrm{T}$ cells are not seen. 
Table 1. Signalment, Schirmer tear test in eye sampled and presumptive diagnosis for each dog from which nictitans gland tissue was harvested in this study.

\begin{tabular}{|c|c|c|c|c|c|}
\hline Case & Breed & Age (years) & Gender & STT in eye sampled & Presumptive diagnosis \\
\hline 1 & ECS & 8 & fn & $2 \mathrm{~mm} / \mathrm{min}$ & Idiopathic KCS 2 years duration \\
\hline 2 & ECS & 10 & fn & $1 \mathrm{~mm} / \mathrm{min}$ & Idiopathic KCS 3 years duration \\
\hline 3 & CKCS & 9 & fn & $0 \mathrm{~mm} / \mathrm{min}$ & Idiopathic KCS 3 years duration \\
\hline 4 & WHWT & 11 & fn & $0 \mathrm{~mm} / \mathrm{min}$ & Idiopathic KCS 5 years duration \\
\hline 5 & WHWT & 8 & fn & $1 \mathrm{~mm} / \mathrm{min}$ & Idiopathic KCS 4 years duration \\
\hline 6 & WHWT & 11 & fn & $4 \mathrm{~mm} / \mathrm{min}$ & Idiopathic KCS 2 years duration \\
\hline 7 & Lhasa & 12 & fn & $0 \mathrm{~mm} / \mathrm{min}$ & Idiopathic KCS 2 years duration \\
\hline 8 & Lhasa & 11 & $\mathrm{mn}$ & $1 \mathrm{~mm} / \mathrm{min}$ & Idiopathic KCS 3 years duration \\
\hline 9 & YT & 12 & fn & $0 \mathrm{~mm} / \mathrm{min}$ & Idiopathic KCS 4 years duration \\
\hline 10 & YT & 8 & $\mathrm{mn}$ & $1 \mathrm{~mm} / \mathrm{min}$ & Idiopathic KCS 3 years duration \\
\hline 11 & Beagle & 8 & me & $0 \mathrm{~mm} / \mathrm{min}$ & Neurogenic KCS 1 years duration \\
\hline 12 & labrador & 7 & me & $0 \mathrm{~mm} / \mathrm{min}$ & Neurogenic KCS 2 years duration \\
\hline 13 & X-bred & 7 & fn & $0 \mathrm{~mm} / \mathrm{min}$ & Neurogenic KCS 6 months duration \\
\hline 14 & WHWT & 11 & fn & $17 \mathrm{~mm} / \mathrm{min}$ & Normal left eye post-mortem \\
\hline 15 & YT & 12 & fn & $20 \mathrm{~mm} / \mathrm{min}$ & Glaucoma \\
\hline 16 & X-bred & 9 & me & $23 \mathrm{~mm} / \mathrm{min}$ & Ocular trauma \\
\hline 17 & WHWT & 12 & $\mathrm{mn}$ & $16 \mathrm{~mm} / \mathrm{min}$ & Uveal melanoma \\
\hline 18 & B Collie & 13 & me & $20 \mathrm{~mm} / \mathrm{min}$ & Uveitis \\
\hline 19 & Bichon & 7 & fn & $17 \mathrm{~mm} / \mathrm{min}$ & Ciliary body adenoma \\
\hline 20 & ECS & 8 & fn & $18 \mathrm{~mm} / \mathrm{min}$ & Normal right eye post-mortem \\
\hline 21 & $\mathrm{X}$-bred & 12 & $\mathrm{mn}$ & $20 \mathrm{~mm} / \mathrm{min}$ & Glaucoma \\
\hline 22 & $\mathrm{X}$-bred & 4 & me & $18 \mathrm{~mm} / \mathrm{min}$ & Ocular trauma \\
\hline 23 & $\mathrm{X}$-bred & 12 & fn & $21 \mathrm{~mm} / \mathrm{min}$ & Normal right eye post-mortem \\
\hline
\end{tabular}

(ECS): English Cocker Spaniel; (WHWT): West Highland White Terrier; (Lhasa): Lhasa Apso; (YT): Yorkshire Terrier; (CKCS): Cavalier King Charles Spaniel; (me): Male entire; (mn): Male neutered; (fe): Female entire; (fn):Female neutered.

Table 2. Total number of cells, inflammatory cells and of CD3- and CD79a-expressing lymphocytes in nictitans gland tissue from all dogs in the study.

\begin{tabular}{ccccc}
\hline Case & $\begin{array}{c}\text { Mean total cell count } \\
\text { per x40 field }\end{array}$ & $\begin{array}{c}\text { Mean total inflammatory } \\
\text { cell count per x40 field }\end{array}$ & $\begin{array}{c}\text { Mean total CD3+ T cell } \\
\text { count per x40 field }\end{array}$ & $\begin{array}{c}\text { Mean total CD 79a+ B cell } \\
\text { count per x40 field }\end{array}$ \\
\hline 1 & $39.1 \pm 11.2$ & $27.4 \pm 6.2$ & $18.2 \pm 5.4$ & $8.6 \pm 0.5$ \\
2 & $60.4 \pm 9.4$ & $24.5 \pm 5.4$ & $16.7 \pm 4.7$ & $6.9 \pm 0.6$ \\
\hline 3 & $32.6 \pm 13.6$ & $29.6 \pm 7.6$ & $15.2 \pm 5.1$ & $13.6 \pm 1.2$ \\
\hline 4 & $53.3 \pm 9.4$ & $45.2 \pm 7.5$ & $19.0 \pm 3.6$ & $25.8 \pm 2.1$ \\
\hline 5 & $57.8 \pm 6.7$ & $53.2 \pm 7.9$ & $16.4 \pm 4.2$ & $35.3 \pm 3.1$ \\
\hline 6 & $42.2 \pm 11.2$ & $27.2 \pm 5.4$ & $17.6 \pm 4.6$ & $8.8 \pm 0.6$ \\
\hline 7 & $61.7 \pm 12.5$ & $30.1 \pm 7.6$ & $8.6 \pm 6.4$ & $21.1 \pm 4.2$ \\
\hline 8 & $56.7 \pm 8.7$ & $48.2 \pm 6.5$ & $16.5 \pm 3.6$ & $29.2 \pm 5.0$ \\
\hline 9 & $75.2 \pm 12.2$ & $46.5 \pm 7.6$ & $12.1 \pm 2.5$ & $33.9 \pm 4.2$ \\
\hline 10 & $72.4 \pm 12.7$ & $54.8 \pm 7.5$ & $16.4 \pm 3.4$ & $37.0 \pm 3.9$ \\
\hline 11 & $19.6 \pm 11.2$ & $14.9 \pm 1.2$ & $4.5 \pm 0.2$ & $9.0 \pm 0.8$ \\
\hline 12 & $28.6 \pm 5.3$ & $21.2 \pm 2.1$ & $7.1 \pm 0.5$ & $13.4 \pm 1.0$ \\
13 & $12.2 \pm 3.1$ & $9.8 \pm 1.2$ & $3.2 \pm 0.3$ & $5.9 \pm 0.4$ \\
\hline 14 & $17.2 \pm 5.2$ & $10.2 \pm 1.1$ & $4.1 \pm 0.5$ & $5.3 \pm 0.6$ \\
\hline 15 & $15.2 \pm 7.3$ & $7.9 \pm 2.1$ & $2.8 \pm 0.6$ & $4.5 \pm 0.3$ \\
\hline 16 & $18.4 \pm 5.6$ & $14.2 \pm 1.9$ & $2.7 \pm 0.7$ & $11.6 \pm 1.0$ \\
\hline 17 & $17.4 \pm 6.2$ & $13.2 \pm 1.2$ & $6.0 \pm 0.3$ & $6.7 \pm 0.5$ \\
\hline 18 & $9.2 \pm 3.4$ & $5.2 \pm 1.2$ & $1.2 \pm 0.2$ & $3.3 \pm 0.4$ \\
\hline 19 & $21.2 \pm 4.3$ & $14.1 \pm 2.1$ & $6.6 \pm 0.9$ & $7.3 \pm 0.5$ \\
\hline 20 & $14.5 \pm .25$ & $9.8 \pm 1.1$ & $2.8 \pm 0.3$ & $6.7 \pm 0.4$ \\
\hline 21 & $12.1 \pm 2.7$ & $5.6 \pm 0.8$ & $0.8 \pm 0.1$ & $4.0 \pm 0.2$ \\
\hline 23 & $8.3 \pm 5.3$ & $4.3 \pm 0.7$ & $1.7 \pm 0.2$ & $3.4 \pm 0.3$ \\
\hline
\end{tabular}


Table 3. Mean and standard deviation of CD3- and CD79a-expressing cells in nictitans gland tissue from normal dogs and those with idiopathic and neurogenic keratoconjunctivitis sicca together with $\mathrm{p}$ value denoting statistical significance of deviation from the control cases with normal tear production.

\begin{tabular}{lccccccccc}
\hline \multirow{2}{*}{ Cells per x40 field } & \multicolumn{3}{c}{ Normal tear production } & \multicolumn{3}{c}{ Idiopathic KCS } & \multicolumn{3}{c}{ Neurogenic KCS } \\
\cline { 2 - 11 } & $\begin{array}{c}\text { Inflammatory } \\
\text { cells }\end{array}$ & CD3 & CD79a & $\begin{array}{c}\text { Inflammatory } \\
\text { cells }\end{array}$ & CD3 & CD79a & $\begin{array}{c}\text { Inflammatory } \\
\text { cells }\end{array}$ & CD3 & CD79a \\
\hline Mean & 9.2 & 5.7 & 7.2 & 38.6 & 28.2 & 11.1 & 15.3 & 7.9 & 11.1 \\
St dev & 3.7 & 2.5 & 2.9 & 12.0 & 4.1 & 8.5 & 5.7 & 1.56 & 1.7 \\
p value cf normal & - & - & - & 0.023 & 0.0025 & 0.049 & 0.092 & 0.17 & 0.29 \\
\hline
\end{tabular}

This difference may help to explain the cyclosporine sensitivity of many cases of iKCS and the cyclosporine resistance seen in cases of neurological KCS. Having said that, the three dogs with nKCS had significantly shorter duration of disease that those with iKCS which may influence the cell populations in the lacrimal tissue. Nevertheless the significantly lower inflammatory cell population in nKCS compared with $\mathrm{iKCS}$ is not unexpected.

It might be argued that using tissue from animals enucleated because of ocular disorders such as uveitis or glaucoma or ocular trauma might give unrepresentative results as a relative tear-film deficiency might be masked by tearing related to ocular pain (Sanchez et al., 2007). In response to such a criticism, we maintain that the ophthalmic examination given showed no signs of current or previous tear film abnormalities such as conjunctival hyperaemia or corneal pigmentation.

It might be argued that the small number of cases from which nictitans gland biopsies were obtained limits the validity of this study. Government legislation in the UK, through the Animal Scientific Procedures Act (1986), precludes surgery in clinical cases which is not specifically for the benefit of the individual animal. This means that nictitans gland biopsy was only possible in animals where other ocular surgery such as PDT is being undertaken and even then only those cases where owners consented to this extra surgery in their pets.

We would argue that the fact that even in a small number of cases these significant differences in infiltrating cell phenotypes were detected, shows that the findings reported here are justified. Clearly though, further work to confirm and widen these findings should be undertaken and it is hioped that this current paper will act as a stimulus to such work, hopefully using frozen sections of tissue on which antibodies recognizing canine CD4 and CD8-expressing cells can be used.

A final question might involve the use of nictitans gland tissue rather than that of the lacrimal gland. While it is the latter which produces the majority of the tears for the ocular surface, it is widely recognised that both glands contribute to lacrimation and that the same pathological processes are likely to be occurring in both cases of canine $\mathrm{KCS}$. It would not be ethically acceptable to sample the lacrimal gland in the living patient, situated as it is in the dorsolateral orbit, but nictitans gland tissue is readily sampled during parotid duct transposition, this tissue availability being at the heart of this study.

\section{Conclusion}

We have shown in this immunohistochemical study of the nictitans glands from dogs with idiopathic KCS, neurogenic KCS and normal dogs, that those with iKCS have a significantly greater population of $\mathrm{T}$ cells than normal dogs or those with neurogenic KCS. These findings confirm that idiopathic KCS in the dog is an immune-mediated T cell-dominated condition which is highly likely to be autoimmune in nature. Further research to evaluate CD4 and CD8 populations in the tear-producing glands of such canine patients should be undertaken.

\section{Conflict of interest}

The authors declare that there is no conflict of interests.

\section{References}

Adamson, T.C., Fox, R.I., Frisman, D.M. and Howell, F.V. 1983. Immunohistologic analysis of lymphoid infiltrates in primary Sjogren's syndrome using monoclonal antibodies J. Immunol. 130, 203-208.

Allison, A.C. 1974. The roles of T and B lymphocytes in self-tolerance and autoimmunity. Contemp. Top. Immunobiol. 3, 227-242.

Berdoulay, A., English, R.V. and Nadelstein, B. 2005. Effect of topical $0.02 \%$ tacrolimus aqueous suspension on tear production in dogs with keratoconjunctivitis sicca. Vet. Ophthalmol. 8, 225232.

Busche, G., Schlue, J. and Georgii, A. 1997. Square sampling. An easy method of estimating numerical densities of cells or particles within a tissue. Anal. Quant. Cytol. Histol. 19, 489-500.

Cobbold, S. and Metcalfe, S. 1994. Monoclonal antibodies that define canine homologues of human CD antigens: summary of the First International Canine Leukocyte Antigen Workshop (CLAW). Tissue Antigens 43, 137-154.

Gao, J., Schwalb, T.A., Addeo, J.V., Ghosn, C.R. and Stern, M.E. 1998. The role of apoptosis in the pathogenesis of canine keratoconjunctivitis sicca: 
the effect of topical Cyclosporin A therapy. Cornea 17, 654-663.

Gelatt, K.N., Peiffer, R.L. Jr., Erickson, J.L. and Gum, G.G. 1975. Evaluation of tear formation in the dog, using a modification of the Schirmer tear test. J. Am. Vet. Med. Assoc. 166, 368-370.

Glenn, J.B. and Lawson, D.D. 1971. A modified technique of parotid duct transposition for the treatment of keratoconjunctivitis sicca in the dog. Vet. Rec. 88, 210-213.

Huang, S.N. 1975. Immunohistochemical demonstration of hepatitis B core and surface antigens in paraffin sections. Lab. Invest. 33, 88-95.

Izci, C., Celik, I., Alkan, F., Ogurtan, Z., Ceylan, C., Sur, E. and Ozkan, Y. 2002. Histologic characteristics and local cellular immunity of the gland of the third eyelid after topical ophthalmic administration of $2 \%$ cyclosporine for treatment of dogs with keratoconjunctivitis sicca. Am. J. Vet. Res. 63, 688-694.

Jabs, D.A., Lee, B. And Prendergast, R.A. 1997. Role of $\mathrm{T}$ cells in the pathogenesis of autoimmune lacrimal gland disease in MRL/Mp-lpr/lpr mice. Curr. Eye Res. 16, 909-916.

Kaswan, R.L., Martin, C.L. and Chapman, W.L. Jr. 1984. Keratoconjunctivitis sicca: histopathologic study of nictitating membrane and lacrimal glands from 28 dogs. Am. J. Vet. Res. 45, 112-118.

Kaswan, R.L. and Salisbury, M.A. 1990. A new perspective on canine keratoconjunctivitis sicca. Treatment with ophthalmic cyclosporine. Vet. Clin. North Am. Small Anim. Pract. 20, 583-613.

Mircheff, A.K. 2003. Sjogrens syndrome as failed local immunohomeostasis: prospects for cell-based therapy. Ocul. Surf. 1, 160-179.

Nell, B., Walde, I., Billich, A., Vit, P. and Meingassner, J.G. 2005. The effect of topical pimecrolimus on keratoconjunctivitis sicca and chronic superficial keratitis in dogs: results from an exploratory study. Vet. Ophthalmol. 8, 39-46.

O'Garra, A., Steinman, L. and Gijbels, K. 1997. CD4+ T-cell subsets in autoimmunity. Curr. Opin. Immunol. 9, 872-883.

Olivero, D.K. 1991. Clinical evaluation of $1 \%$ cyclosporine for topical treatment of keratoconjunctivitis sicca in dogs. J. Am. Vet. Med. Assoc. 199, 1039-1042.

Robinson, C.P., Cornelius, J., Bounous, D.E., Yamamoto, H., Humphreys-Beher, M.G. and Peck, A.B. 1998. Characterization of the changing lymphocyte populations and cytokine expression in the exocrine tissues of autoimmune NOD mice. Autoimmunity 27, 29-44.

Sanchez, R.F., Innocent, G., Mould, J. and Billson, F.M. 2007. Canine keratoconjunctivitis sicca: disease trends in a review of 229 cases. J. Small Anim. Pract. 48, 211-217.

Scagliotti, R.H. 1991. Neuro-ophthalmology. In: Veterinary Ophthalmology, $2^{\text {nd }}$ edn (ed. Gelatt KN) Lea \& Febiger; Philadelphia, pp: 706-743.

Williams, D.L. 1997a. A comparative approach to topical cyclosporine therapy. Eye 11, 453-464.

Williams, D.L. 1997b. Studies of canine leucocyte antigens: a significant advance in canine immunology. Vet. J. 153, 31-39.

Williams, D.L. 2008. Immunopathogenesis of keratoconjunctivitis sicca in the dog. Vet. Clin. North Am. Small Anim. Pract. 38, 251-268.

Williams, D.L., Hoey, A.J. and Smitherman, P. 1995. Comparison of topical cyclosporin and dexamethasone for the treatment of chronic superficial keratitis in dogs. Vet. Rec. 137, 635-639.

Yoshida, A., Fujihara, T. and Nakata, K. 1999. Cyclosporin A increases tear fluid secretion via release of sensory neurotransmitters and muscarinic pathway in mice. Exp. Eye Res. 68, 541-546. 